\title{
TRAJETÓRIA PARA O CURRÍCULO - HISTÓRIA PESSOAL E POLÍTICA SOCIAL EM ESTUDOS CURRICULARES ${ }^{1}$
}

\section{Ivor Goodson}

\section{RESUMO}

Neste artigo, o campo de estudos de currículo delineia-se por uma escrita biográfica e reflexiva com a qual o autor destaca movimentos de sua vida profissional a partir de registros escritos e lembranças.

\section{PALAVRAS-CHAVE}

Currículo; História de vida; Formação de professores

\section{COMING TO CURRICULUM PERSONAL HISTORY AND SOCIAL POLITICS IN CURRICULUM STUDIES}

\section{ABSTRACT}

In this article, the field of curriculum studies is outlined through a bigraphic, reflexive writing, with which the author emphasises movements of his professional life based on written registers and memories.

\section{KEY WORDS}

Curriculum; Life history; Teacher education

\footnotetext{
${ }^{1}$ Tradução do original em inglês por Mara Verônica Suassuna Lopes. Revisão Técnica: Antonio Carlos Amorim.
} 


\section{A VIDA ANTES DO MAGISTÉRIO}

Minha visão e versão pessoais sobre ensino em geral e o currículo, em particular, foi muito influenciada por minhas próprias origens sociais. Nasci em 1943, em Woodley, perto de Reading, Berkshire. Meu pai era encanador de gás e minha mãe trabalhava, na época, em uma fábrica de munições. Meu pai era o mais jovem de 13 filhos e foi precedido por 12 irmãs. O pai dele aparece na maioria das certidões de nascimento das crianças como 'operário desempregado', mas duas vezes, em épocas melhores, como 'assentador de trilhos de trem'. Morreu (num velho albergue para pobres) antes do meu nascimento. Sua mãe era lavadeira e viveu até 98 anos. Na família da minha mãe, havia sete crianças. Seus pais passaram por vários empregos até que, em 1929, abriram um café em um distrito do proletariado de Reading, onde minha mãe e meu pai se conheceram.

Quando eu fui à escola pela primeira vez, aos seis anos, ainda não sabia ler. No entanto, achei a escola uma experiência fascinante e ao mesmo tempo perturbadora. Em minha cidadezinha, não se ia à escola contente. Ainda me lembro da longa caminhada para a escola no primeiro dia de aula, quando vi um dos meus colegas, Paul Sharp, se agarrando às grades do portão de sua casa e gritando desesperadamente enquanto sua mãe tentava tirá-lo e levá-lo ao seu primeiro dia de ‘edificação formal, do Estado’ (frase de um tio!).

Alguns anos atrás, tentei resumir meus 'pontos pessoais de entrada’ para os estudos sobre escolarização. Então, deixe-me continuar a história com uma citação mais longa: Meus próprios pais presenciaram a realização do governo de 'seu' partido trabalhador após a guerra, demonstrada principalmente através do novo sistema de ensino, o qual foi oferecido a mim e aos filhos de outras famílias operárias. Aí, disseram-me que seria a chance de aprender, uma oportunidade de compreender o mundo no qual eu estava crescendo.

Contudo, desde o princípio, experienciei estranhas contradições, pois apesar de estar lá para aprender, a maioria das questões para as quais buscava respostas não estavam no programa escolar. Eram principalmente questões infantis, porém foram elas que despertaram minha compreensão de mundo, no momento. 
Essas eram as coisas sobre as quais conversávamos em casa: Por que meu pai trabalhava tanto? Por que eu não o via de manhã, nem até tarde da noite? Por que minha mãe tinha que trabalhar para 'me sustentar'? Por que todos os campos em que eu brincava estavam sendo transformados em mais, e cada vez maiores 'conjuntos habitacionais' da prefeitura? Por que tínhamos que caminhar (ou, mais tarde, ir de bicicleta) por mais de cinco quilômetros para chegar à escola? Por que a escola ficava numa cidade mais 'chique’ e não onde eu morava? Por que as crianças da minha cidade eram tratadas de maneira diferente daquelas vindas de uma escola da cidade vizinha? Na época, estes eram aspectos que faziam parte do meu mundo; mas por que nunca falávamos sobre eles, quanto mais aprender sobre isso na escola?

Minhas preocupações a respeito de educação aumentaram quando entrei na escola secundária. Terminei a escola primária e fui enviado para uma grammar school ${ }^{2}$ (novamente, muito distante da minha cidade). Todos os meus amigos agora estavam freqüentando a nossa escola: uma escola secundária moderna. O longo percurso percorrido até a escola através dos conjuntos habitacionais, usando uma jaqueta listrada azul e um chapéu com borla amarela consolidaram um fascínio incurável pelo ensino. (Tal fascínio durou mais que a jaqueta e o chapéu, que eu levava empacotados na bolsa do selim da minha bicicleta e os vestia no estacionamento de bicicletas da escola).

Na grammar school, o currículo fez meu senso de dicotomia da primary school parecer grotesco. Ali, não apenas o conteúdo era estranho e entediante, mas também a própria forma de transmissão e a estrutura (assim como a formação discursiva) eram extremamente confusas. Minha experiência com a educação era como a de aprender uma segunda língua. Um fator importante para eu me sentir culturalmente deslocado era o currículo escolar.

Na escola, eu definhava: de nove exames, não passei em oito. Aos quinze anos, fui trabalhar em uma fábrica de batatas fritas. Depois, contudo (devido à intervenção de um professor), retornei à escola e, embora ainda perturbado com a sensação de alienação às disciplinas, comecei a fazer testes de 'aprendizagem mecânica' e de memória, que eram oferecidos juntamente com os exames regulares.

\footnotetext{
${ }^{2}$ Nota do revisor técnico: grammar school refere-se ao segundo ciclo do ensino elementar, cujo primeiro departamento é a primary school.
} 
Obtive graduação universitária (em História Econômica) e prossegui até cursar parte do doutorado (a respeito dos imigrantes irlandeses na Inglaterra Vitoriana), mas em 1968 abandonei totalmente a vida acadêmica por continuar a sentir uma dicotomia entre a 'vida’ e os ‘estudos’. Tomei esta decisão a partir de dois artigos que li - um escrito por Basil Bernstein em New Society, 'Open Schools, Open Society'; o outro por Barry Sugarman sobre as culturas dos alunos da escola secundária (BRITISH JOURNAL OF SOCIOLOGY, 1967).

Estes artigos mostraram-me que havia modelos de estudo acadêmico nos quais as experiência quotidianas de alunos comuns e das pessoas poderiam ser investigadas. Em outras palavras, onde minha experiência de vida e minhas questões intelectuais a respeito daquela experiência poderiam finalmente ser reconectadas. Porém, assim como antes, tive que abandonar meus interesses intelectuais para conseguir passar nos exames; novamente, aqui, tive que abandonar uma carreira acadêmica para que eu e os estudos pudéssemos reaver algum grau de autenticidade.

A decisão de abandonar a carreira acadêmica deu-me um redirecionamento essencialmente positivo. Tendo identificado o tipo de trabalho epitomizado em Bernstein and Sugarman, vi as 'comprehensive schools' ${ }^{3}$, recentemente organizadas como o local onde eu gostaria de trabalhar. Nelas, minha própria formação e experiência em classe poderiam se combinar com as dos meus alunos, através de uma 'linguagem comum’ de diálogo entre o educador e o educado. Para a nova geração de alunos que vinham de lares operários, deveria haver algo além da alienação infiltradora que eu havia experienciado na escola.

Estas eram, no momento, as esperanças que eu possuía quando deixei meu lar de classe operária, numa cidadezinha de Berkshire, para me estabelecer em outra cidadezinha de Leicestershire e começar a dar aula em uma 'comprehensive school' (GOODSON, 1988). Um aspecto que não está suficientemente descrito neste relato é meu envolvimento crescente com a cultura jovem da época, que se voltava a um hedonismo geral e à imersão na música pop. Este envolvimento - como se observa no artigo de Sugarman, mencionado acima - freqüentemente andava lado a lado com a rejeição ao currículo da escola formal pelos alunos de classe operária. The Rolling Stones era uma banda da cidade (Marianne Faithful, namorada de Mick Jagger, freqüentava uma escola local), The Who e

\footnotetext{
${ }^{3}$ Nota do revisor técnico: comprehensive schools são escolas de ensino médio inglesas não especializadas e destinadas principalmente às classes trabalhadoras, na medida em que aceitam alunos sem procedimentos acadêmicos de seleção. Para outras discussões a respeito da relação entre Comprehensive schools e currículo, ver Goodson (2007).
} 
The Animals tocavam lá regularmente. Eles e várias outras bandas começaram a desenvolver uma marca de Rock indígena, o qual surgiu com toda a força em grande parte do mundo ocidental. Quando me mudei para a universidade de Londres, meu interesse continuava (coincidentemente, Mick Jagger também freqüentava a Escola de Economia de Londres, na mesma época, e lembro-me de várias noites agradáveis no 'Three Tuns pub’ com ele). Passei um bom tempo no Marquee Club e vi bandas como o The Who aperfeiçoando sua arte.

Depois que me mudei para Leicester, encontrei outro vigoroso cenário do Rock. O Il Rondo Club era esplêndido, e muitas das bandas nacionais e locais tocavam lá. As duas bandas da cidade, Family e Showaddywaddy, surgiram neste cenário e tornaram-se amplamente populares. O pub local de Countesthorpe, o Railway Tavern, possuía uma jukebox com um maravilhoso estoque de músicas, e lá, à noite, a cultura jovem da classe operária do tipo que eu conhecia desde os 13 anos de idade, dominava a cena.

\section{ENSINANDO EM LEICESTERSHIRE}

Em setembro de 1970, a história chega a uma pequena cidade na planície do sul de Leicester. Eu havia visto um anúncio no suplemento educacional do Times e me candidatei ao emprego. Na época eu não sabia nada sobre a importância da escola de Countesthorpe, pois ela era uma experiência muito radical em educação pública para alunos na faixa etária de 11 a 18 anos. Lembro-me de quando fui à entrevista em Leicester com minha namorada, da Escola de Economia de Londres, Anna Bicat. Fui entrevistado às 14:30h por Tim McMullen e Mike Armstrong. Aparentemente, tinham acabado de almoçar informalmente no restaurante da prefeitura e a entrevista transcorreu muito bem. Quando Anna e eu chegamos de volta ao nosso apartamento, havia um telegrama nos aguardando (que guardo até hoje - fontes históricas, item 203!) que dizia 'gostaríamos de contratá-lo. Favor confirmar aceitação por telefone.’ Adorei o estilo deles e telefonei imediatamente.

Quando foi regularizada a documentação com a escola, comecei a me dar conta de que esta era realmente um escola altamente incomum e inovadora (MCMULLEN, 1970). 


\section{COUNTESTHORPE COLLEGE}

\section{OBJETIVOS PRINCIPAIS}

1. Para aqueles na idade escolar: dar-lhes a mais ampla possilidade de desenvolverem suas habilidades, realizações e postura para que através delas sejam capazes de encontrar estas ações - intelectuais, emocionais, sociais - as quais trarão as maiores satisfações para suas vidas como adultos, o que ocorrerá entre os anos de 1975-2025.

2. Para aqueles que deixaram a escola: para fornecer-lhes oportunidades, tanto individualmente quanto em grupos, de encontrar satisfações maiores na vida que levam agora e que levarão no futuro.

A interpretação plena destes objetivos gerais será trabalhada pelos funcionários, pelos alunos e pela comunidade ao longo dos anos; contudo, certas considerações ficam claras desde o princípio:

(i) Será necessário adequar as pessoas para fazerem parte da 'superestrutura' da sociedade - a seção econômica e política - a educação precisa se adaptar aos novos padrões tecnológicos e sociais, que estão em constante mutação, a um mundo onde a indústria e o comércio exigem profissionais cada vez melhor preparados, tecnólogos, técnicos de nível médio, executivos, planejadores e administradores, ao invés de trabalhadores habilitados, semi-habilitados e não-habilitados; a uma demanda crescente por profissões de prestação de 'serviços' de todos os tipos, que envolvem principalmente relações humanas; a um mundo onde para talvez a maioria, o tempo despendido no ‘trabalho’ e o interesse por ele declinarão rapidamente.

(ii) Será bastante necessário - ou talvez até mais - preparar as pessoas para terem uma vida mais rica individualmente e em grupo fora da 'superestrutura' da sociedade, tanto por isto agora ser economicamente possível, como também porque as pressões mostram que estamos cada vez mais insatisfeitos com a abordagem social puramente 'tecnocrata'; que menos pessoas ficarão contentes com seu trabalho; e que o trabalho ocupará uma parte cada vez menor do tempo e do espaço em nossas vidas. 
Estas duas ‘orientações’ implicam uma reavaliação e uma mudança no currículo, nos métodos, nas relações de autoridade e na organização.

\section{“LINHAS GERAIS DE DESENVOLVIMENTO}

1. O desenvolvimento do colégio como uma comunidade na qual os estudantes da Escola Superior, os funcionários - profissionais e outros - e os adultos da comunidade local trabalham juntos ao invés de em compartimentos. Isto implica: tomadas de decisão 'participativas' e não 'autoritárias'; o enfraquecimento das fronteiras que separam a comunidade e uma verdadeira mistura de adultos e estudantes num dia mais amplo que inclui a escola e a comunidade.

2. A reavaliação e a seleção do currículo em termos de sua relevância. Isto pode envolver: conteúdo diferente para certas disciplinas, como, por exemplo, matemática, física; desenvolvimento de trabalho interdisciplinar e baseado em resolução de problemas, ao invés de apenas no conteúdo, em algumas áreas - em particular, em disciplinas humanas e de criatividade artística; a introdução de novos especialismos, talvez, como partes de áreas interdisciplinares, como, por exemplo, sociologia, psicologia, e o desaparecimento de - ou uma diminuição considerável de - outras áreas.

3. Uma reavaliação da organização em termos de quem toma as decisões e em que nível, e uma nova organização acadêmica em ‘áreas’, em lugar de em departamentos de disciplinas.

4. Uma reavaliação dos métodos pelos quais os alunos aprendem, e o tamanho dos grupos nos quais eles estão organizados, com ênfase na aprendizagem individual ou de grupos pequenos, mais tempo 'independente' disponível para atividades escolhidas pelos alunos, mais cooperação entre os professores, e a utilização maior de novos meios.

5. O desenvolvimento de uma organização que permitirá o desenvolvimento de indivíduos dentro de um plano pessoal adequado a cada um e na velocidade apropriada a eles, sem classificar as crianças mais do que é essencial, em grupos 
‘aptos' e 'menos aptos'.

6. Uma organização pastoral que será o principal contato para os pais e pelos quais um mestre de responsabilidade geral controla aproximadamente 200 alunos, ajudado por uma equipe de etagiários/tutores que também ensinam os alunos em pelo menos uma disciplina.

7. O desenvolvimento de uma forma de governo tanto dentro da escola como na comunidade, pela qual aqueles que participam da vida do colégio determinam a política a ser adotada” (MCMULLEN, 1970).

Quando o caráter da escola começou a surgir, pude ver por que as referências dos meus estagiários/tutores de currículo do Instituto de Educação podem ter me ajudado a continuar no quadro de professores da escola. As referências tinham sido claras sobre pontos fortes e fracos:

\begin{abstract}
O ponto mais forte do Sr. Goodson é sua habilidade de se relacionar com os alunos individualmente. Ele trata as crianças com seriedade quando isto se faz necessário; ouve o que têm a dizer e os incentiva a falar bastante, mesmo em ocasiões em que normalmente se recusariam. Ele também é capaz de mostrar que seus padrões não são o que deveriam ser, sem criar antagonismo. Possui um grande senso de humor e pode brincar com os alunos sem, contudo, perder o respeito dos mesmos. Embora tenha sido um aluno 'popular e cativante', pode às vezes parecer desinteressado para as pessoas que seguem tudo 'como manda o figurino'. Ofendeu um ou dois professores em Hammersmith (a escola onde estou estagiando) desta forma, mas é importante enfatizar que as partes 'ofendidas' se sentiram ameaçadas pelo sucesso dos métodos de ensino do Sr. Goodson, os quais haviam envolvido os alunos de uma forma que eles jamais conseguiram com suas técnicas expositivas. ${ }^{4}$ (TUTOR EDUCACIONAL, 1970).
\end{abstract}

Esta pedagogia emergente era praticada em uma escola em Hammersmith, Latymer Upper, onde eu fiz meu estágio de ‘formação de professor’ para obter meu diploma em Educação (PGCE), no Instituto de Educação, uma escola muito convencional e conservadora. No entanto, em Countesthorpe são bastante claros os ingredients de uma pedagogia definida de forma mais consciente, na minha opinião. Na verdade, fico surpreso por ver como esta referência é profética. Além do mais, havia assumido que meu estilo informal e o uso do humor tinham de certa forma ‘emergido' em Countesthorpe. Estava claro que este não era o caso, embora a atmosfera aberta de lá e o ethos geral devam ter me

\footnotetext{
${ }^{4}$ Reference, Education Tutor, Institute of Education, University of London, 1970.
} 
incentivado a 'me soltar' mais. O estilo de vida e a pedagogia tronaram-se independentes.

Quando comecei a lecionar na escola, um pesquisador etnográfico passou um certo tempo assistindo a alguns de nós dando aula. Conseguiu captar rapidamente a essência da minha pedagogia. Ainda me admiro em quão rapidamente ele pôde enxergar o que tantos alunos percebiam, mas que tão poucos educadores conseguiam compreender:

\begin{abstract}
Quando o observo dando aula, percebo claramente que há algo nele que o difere de outros professores, mesmo de outros também brincalhões, como Liz. Ivor não parece representar a escola como fazem outros professores. Ele dá a impressão de simplesmente estar lá porque é um emprego. De alguma forma sutil e indefinível, ele transmite um tipo de insolência que é característica apenas de alunos, nunca de professores. Há algo de confidante, arrogante e profundamente irreverente na forma que ele age. Parece não ter qualquer responsabilidade pelo ethos nem pela cultura de lencionar. Não é apenas porque xinga, pois a maioria dos professores da escola o faz, e alguns muito mais que ele. Não porque ele brinca, porque outros professores também. Não são seus trajes ou sua aparência, que são convencionais, comparados com os de vários outros funcionários. É uma característica inerente sua, algo em todo o seu estilo pessoal (WALKER, 1973).
\end{abstract}

Ele igualmente captou meu estilo de vida. Lembro-me que 'o pobre coitado' teve que dormir várias vezes num colchão em um cômodo que, mais tarde, descreveu em seu relatório para a Ford Foundation (tanto pela vida 'no campo'):

\begin{abstract}
Ivor divide o apartamento com dois (?) outros professores. Seu quarto é um tanto caótico. Um aparelho de som enorme (muito admirado por seus alunos, que freqüentmente são encontrados usando-o). Uma coleção enorme de discos de rock (nenhum de jazz), da qual 10 ou 11 LP's pareciam estar em uso mais ou menos constante. Revistas empilhadas pelo quarto, sendo a mais usada delas Let it Rock, a qual continha vários artigos escritos por Ivor. Livros sobre a história da indústria local (Ivor era co-autor de um deles), sobre a Rússia, e uma coletânea de sociologia (Bernstein's Class, Codes and Control, Nell Keddie). Quase todo o chão era tomado por um velho colchão, o resto por meias, uma raquete de tênis, tênis (teriam sido brancos um dia?), um grande baú, cartas variadas (uma delas solicitando o cargo de 'professor de geografia'). No papel de parede descorado, um pôster dos Beatles e um relatório escolar feito em seu nome e assinado por um aluno ('Poderia se sair melhor se se esforçasse mais') (WALKER, 1973).
\end{abstract}

Mas como o estilo de vida pessoal e a pedagogia interagem? Até que ponto a pessoa influencia o papel de professor? Surge aqui o tema da indivisibilidade. 
Muitas vezes, os professors sentem as contradições entre eles mesmos como professores e como pessoas. Assim, o professor que é amigável no parque ou no corredor, mas que é frio na sala de aula, ou aquele que permite que haja uma atmosfera relaxada em algumas partes da aula, mas que sabe quando ser sério. Nós, assim como aqueles que o conhecem melhor, não detectamos nada disso em Ivor. Ele parece igual em quase todas as situações. (WALKER, 1973).

Em uma série de notas e cartas ${ }^{5}$ escritas em 1973, tentei explicar em detalhes por que defendia tal pedagogia e o que faltava neste e em outros relatos etnográficos. Acho que se deve explicar muito mais a respeito da cultura jovem. É exatamente como algo que distrai a sua atenção, e que você acabou de se ver.

Certamente, o ponto importante é que, para toda a minha geração (e a sua!), a cultura jovem era o caminho para um estilo de vida inteiramente radical ${ }^{6}$. Ela agiu no sentido de derrubar estereótipos de classe e outros. Agora, uma vez que isso é assim e que eu apóio este estilo de vida, deveria ocorrer também que, se os professores que tiverem experiência com a cultura jovem transmitirem isso em sua maneira de educar, os esterótipos normais poderão se dissolver. A cultura jovem e a classe operária são muito semelhantes de uma maneira geral. Isto é particularmente verdade, eu diria, em relação à autoridade. Portanto, um professor que tenha experiência com a cultura jovem $e$ transfira isso à sua maneira de ensinar (quer ele seja um beatnik de fim-de-demana ou como estilo de vida!) deverá ficar bem situado e em empatia com os jovens de classe operária. É interessante mencionar Lennon e Best - eles simbolizam uma faixa da cultura jovem - o rebelde (neste caso, penso que com causa!). Acho difícil de acreditar que muitos jovens de classe operária levarão a sério professores que levam a escola a sério. Isto é, isto apenas no sentido da ‘imagem'. Algo que você nem mencionou - e contudo faz parte do vocabulário de muitos jovens de classe operária. As escolas são 'objetos de ódio’ na linguagem interna dos jovens. Você as freqüenta mais ou menos com a mesma disposição em que se vai à fábrica isto é, quando se é adolescente. Aprende a odiar cada hipocrisia e falácia que elas representam. Portanto, um professor que se identifica inteiramente com a escola encontrará uma reação semelhante dos alunos (carta a WALKER, 1973).

Duas outras anotações que encontrei em velhos pedacinhos de papel de 1972 explicam melhor sobre meu método e ressaltam as preocupações predominantes neste estágio

\footnotetext{
5 Personal Diary, 1973.

${ }^{6}$ Nota do revisor técnico: todo o parágrafo que segue a esta frase são extratos da carta que Ivor enviou a Walker, em 1973.
} 
da minha vida de educador. Apresento-as em seguida endereçadas à juventudade da classe operária.

\section{Para o Jovem de Classe Operária}

"1. A pessoa vem antes da profissão, ao decidir se você aprende com o professor. A aprendizagem só acontecerá se a pessoa for acessível e aceitável. Este é o primeiro pressuposto.

2. A pessoa pode ser julgada em vários níveis. Certos fatores parecem predispor os jovens a gostarem dos professores.

(a) A habilidade de brincar e de ser alvo de brincadeiras - um mecanismo de 'teste' dos jovens de classe operária (Scwartz chama isso de 'sonoridade' entre os jovens negros de Nova lorque)

(b) Uma irreverência, revolta, como a seus heróis.

(c) Uma aceitação geral de risos e diversão como ingredients fundamentais à vida.

Existem outros símbolos que podem sugerir empatia com a cultura, baseados na maneira de andar e se mover, e 0 reconhecimento de 'distanciamento' de certas situações definidas (por exemplo, quendo o professor estiver no restaurante, na hora do almoço).

Já que o papel do professor está associado ao produto que ele está fornecendo, então depende muito do produto. A maioria encontra poucos pontos de referência ou relevância em sua 'disciplina'. Então, a única maneira de fazer com que os jovens de classe operária façam as pazes com a escola é através da própria pessoa do professor, divorciada do seu papel. 0 mundo estranho da escola só pode ser explorado através da relação que a criança tem com o professor. 0 professor precisa existir e definir um contexto social e uma relação que a criança ache complacente. Isto implica que 0 professor esteja suficientemente ciente da cultura da criança para incluir uma porção de símbolos familiars que podem tornar a sala de aula um ambiente suficientemente familiar.

(1) O que eu penso que se está dizendo é que o primeiro estágio no aprendizado no processo de aprendizagem é 0 estabalecimento de uma relação de 'conhecimento'. 0 aspecto sócio-pastoral precede 0 acadêmico. Embora para a maioria dos jovens de classe operária esta relação esteja implícita, e suspensa na expecativa de aplicabilidade.

(2) Sem esta relação, não importa qual a pedagogia, a transmissão ou a transformação, sempre haverá um grande número de fracassos. Simplesmente porque eles nunca 'entraram num acordo' sobre o significado do professor. Então, o que ele evocar não terá a ver com o potencial da criança.

(3) A relação não é apenas o pré-requisito para a transmissão. Ela deve, ao ser estabalecida, afetar a natureza desta transmissão. O ponto crítico é aquele no qual a criança SE COMPROMETE; daí em diante, o professor é um cooperador. $O$ aprendizado torna-se uma possibilidade ${ }^{7 ”}$ (anotações pessoais 1973 - 1974).

O ponto mais óbvio que emergiu dos meus artigos científicos, anotações e conversas gravadas é o que pode ser chamado minha 'cronologia de interesses' ou 'seqüência de interesses'. Muito claramente, nos primeiros anos na escola, meus interesses eram primeriamente concentrados na sala de aula - como fazer para as crianças se

\footnotetext{
7 Personal notes circa, 1973-1974.
} 
comprometerem com a aprendizagem, particularmente a maioria das crianças que vinham de lares de classe operária. No processo de encontrar meu caminho como professor, criando meu próprio ‘estilo’, estas eram minhas primeiras preocupações. No cerne do processo de me tornar um professor, estava esta questão da orientação pedagógica. Porém, acredito que a questão da orientação pedagógica contém um amálgama implícito de outros valores e posições. A orientação pedagógica derivava claramente, eu penso, em grande parte de pontos fortes e fracos pessoais, bem como de assuntos cruciais de formação, tais como classe social e origens regionais. Porém, o mais importante é que eu acredito que as questões de orientação pedagógica crucialmente antecipam e circunscrevem julgamentos subseqüentes a respeito de estilos de currículo, governância e organização escolares que dependem de julgamentos políticos, tais como que tipo de escolas, que tipo de alunos devem ser escolhidos e custeados.

Devo ressaltar que não estou interessado aqui em apresentar provas quanto à qualidade da minha prática de sala de aula: sobre se eu era um bom ou um mau professor. Meu interesse é caracterizar o desenvolvimento da minha visão sobre o estilo pedagógico, assim como a justaposição do estilo pessoal com o pedagógico. O argumento que defendo é o de que esta orientação pedagógica e o senso interdependente de estilo de vida pessoal é uma consideração crucialmente importante nos estilos de currículo e ensino a que nos afiliamos. Em resumo, na combinação entre o estilo de vida pessoal e a orientação pedagógica, estão muitas das origens de predisposições dos professores. Predisposições que existem para apoiar versões particulares de disciplinas de planejamento de curso, projetos curriculares, procedimentos de avaliação, assim como decisões administrativas, decisões políticas e assuntos de interesse da comunidade.

\section{ADENTRANDO NOS ESTUDOS DE CURRÍCULO}

Nos primeiros anos de magistério, minha preocupação principal era claramente com os 'assuntos de sala de aula' - como o desenvolvimento de um estilo e uma orientação pedagógica. Porém, ao desenvolver esta orientação pedagógica, eu estava criando, de maneira implícita, e favorecendo uma afiliação a estilos de currículo, avaliação e ensino.

Em parte, esta 'entrada no currículo', esta necessidade de examinar e questionar estilos existents de currículo fez parte de uma busca institucional que teve 
continuidade nos primeiros anos de Countesthorpe. Porque se as primeiras relações radicais e pedagógicas fossem sobreviver, novos estilos de currículo e avaliação seriam necessários. Portanto, mesmo os professores em experiência, como eu, estavam envolvidos em desenvolver novos planos de ensino para avaliação no Modo $3^{8}$. Uma preocupação primordial no desenvolvimento do currículo era a necessidade de comprometer os alunos como vimos, isto era minha principal preocupação na sala de aula, então era inevitável que isso fosse entrar no planejamento do currículo. Na sala de aula, a sala de 'habilidades mistas', nós procurávamos envolver todos os alunos - assim, buscávamos um currículo que refletisse esta intenção 'abrangente'.

Escrevendo, em novembro de 1973, coloquei em prática algumas das minhas idéias experimentais: por exemplo, sobre o tema da autonomia do aluno.

Após justificativas proféticas generalizadas, uma justificativa final é a de que a autonomia do estudante pode servir para resolver alguns problemas educacionais que confrontam a educação moderna. São muitos e variados os problemas de ensinar grupos com habilidades e formações dieferentes. A maior parte destes problemas, contudo, está ligada à falta de motivação dos alunos para aprender e, intimamente aliada a isto está a relevância questionável sobre o que eles são solicitados a aprender. Como vimos, mesmo depois do desenvolvimento de novos currículos, os professores ainda consideram que devem controlar todos os aspectos da situação de aprendizagem dos alunos. Esta total monopolização pelos professores, creio que seja uma das principais causas para a sensação de alienação e desinteresse dos alunos. O monopólio deve ser quebrado para que se instaure seu interesse. Tomemos como exemplo: os professores estão cada vez mais cientes de que a 'relevância' é um critério importante para a consideração dos estudos escolares. Os professores estão divididos perante seus alunos pelo imenso golfo geracional e, normalmente, pelo grande abismo da diferença de classes. Diante disso, é declaradamente absurdo para o professor insistir na decisão sobre quais coisas irão atrair os alunos com base na relevância. A relevância é apenas uma das várias razões para a aprendizagem, mas, como acontece com muitas outras coisas, os alunos estão em posição melhor que os professores para fazerem julgamentos. Não se está dizendo que se deva dar aos alunos o direito de decidir tudo sobre como aprender, mas sim que o monopólio atual do professor sobre tais decisões deve ser

\footnotetext{
${ }^{8}$ Exames Modo 3 eram aqueles em que os professores representavam uma parte central na a definição do planejamento de curso e na realização de avaliações.
} 
quebrado. "O que é necessário é uma visão de aprendizagem que seja como um exercício negociável e colaborador entre o professor e o aluno. O currículo pode então ser visto como algo que, por um lado, se desenvolve a partir da exigência dos alunos de algo relevante, útil e interessante e, por outro lado, da exigência dos professores de algo que amplie os horizontes dos alunos e ofereça abertura para novas formas de entendimento”.(GOODSON, 1973a, p. 8)

As exigências dos alunos de algo relevante levaram a agrupamentos de interesses finitos e relativamente claros. Uma área era seu interesse por desenvolvimentos em sua própria comunidade. Estavam ocorrendo grandes mudanças em Leicester e na região campestre, e os alunos estavam ansiosos para saber o que estava acontecendo e para investigar as causas das mudanças. Isto levou a uma série de estudos e investigações urbanas e da comunidade, as quais eu descrevi em detalhes, na época (GOODSON, 1973b).

Minha percepção das coisas na época era evidente nos artigos que escrevia. Estas eram 'comprehensive schools' pioneiras - nossa chance era a de definir novos currículos que comprometessem todos os alunos e pudessem levar à 'educação de todos'. Acreditava (e ainda acredito) apaixonadamente no direito de todas as crianças a uma educação completa. Também acreditava na retórica da educação compreensiva, na provisão de oportunidades educacionais iguais para todas as habilidades e classes sociais. Diante desta crença (sem dúvida, ingênua), a tarefa que teríamos que executar era clara. Tínhamos que definir uma nova extensão para os currículos escolares e novos critérios de avaliação que incluiriam conteúdo e temas que comprometeriam todos os alunos. Meu próprio envolvimento na definição dos novos currículos em estudos urbanos e da comunidade fazia parte deste projeto otimista de redefinição.

Quando assumi o posto de Diretor da Faculdade de Humanas em Milton Keynes, passei um bom tempo definindo os novos currículos desta maneira. Um novo nível de formação em Estudos da Comunidade foi definido e aceito pelo comitê de avaliação, no primeiro ano. Neste momento, o esboço do meu planejamento para a Faculdade estava razoavelmente explícito em relação aos meus valores sobre currículo.

O pré-requisito para o envolvimento no trabalho acadêmico da faculdade ou na comunidade, com e sem a escola, é possuir um senso de autoconfiança e dignidade. Desta forma, posicionamos o aluno e sua experiência no centro do processo de aprendizagem; nós 
reconhecemos que não podemos ensinar sem que ele aprenda, não podemos elaborar objetivos sem considerar a sua motivação.

A Faculdade de Humanas tem dois objetivos:

1) Dar ao aluno um senso de sua própria unicidade e dignidade para auxiliar seu autoconhecimento e autoconfiança. Isto requer:

a. um pouco de exploração sobre a experiência de vida do próprio aluno até o momento e

b. a utilização de estratégias de aprendizagem que dêem ao aluno alguma autonomia para dirigir sua própria aprendizagem.

2) Envolver os alunos das comunidades emergentes de Milton Keynes e da escola. Ajudá-los a identificar-se com seu novo ambiente e a usar suas instalações comunitárias. Isto pressupõe a exploração das comunidades de Milton Keynes e do distrito, em vários níveis.

As estratégias de aprendizagem associadas a estes objetivos maiores envolvem dois tipos de habilidades:

a. Habilidades sociais, isto é, uma compreensão sobre o conceito de 'compartilhar'.

b. Habilidades acadêmicas (GOODSON, 1974).

Porém, em 1974-5, estava se tornando cada vez mais claro que os novos currículos definidos em prol da 'educação para todos' encontravam grande oposição. Os Black Papers, lançados pela primeira vez em1969, começaram a tecer críticas contra as novas iniciativas e a reivindicar o retorno às disciplinas e ao ensino tradicionais. As novas iniciativas de novo currículo não estavam, é claro, isentas de falhas e insuficiências, mas, naquele momento, estava bastante claro que estávamos preparados para ir contra grandes barreiras estruturais.

De certa forma, acredito que estávamos buscando a retórica da 'educação abrangente’, ‘educação para todos’, para sua conclusão lógica. Porém, viemos a compreender que lógica e política chocavam-se bastante rapidamente na prática. O currículo e a avaliação tornaram-se o terreno onde a 'educação para todos' se chocava com as novas experiências, como a dos Estudos de Comunidade. Em resumo, quando a prática igualitária chocou-se com os interesses meritocráticos. Em 1976, o Ruskin Speech, feito pelo Primeiro Ministro do partido operário, James Callaghan, foi conclusivo em deixar claro que o experimento ‘compreensivo’ não deveria ser empreendido com seriedade. Alguns eventos subseqëntes, é claro, confirmaram isto.

Minha sensação crescente de frustração pessoal em face a esta reestruturação política levou-me, em 1975, a ingressar em um projeto na Universidade de Sussex, pela educação ambiental urbana e da comunidade. Em outras palavras, uma chance para explorar 
mais profundamente meu interesse crescente em promover os novos currículos que havia definido em duas escolas compreensivas em que havia trabalhado. Porém, este projeto deume a chance de fazer muito mais que isso. Ele permitiu-me estudar a fundo (para um Ph.D) a política de alteração de currículo. No primeiro ano, sentei-me para escrever minhas opiniões a respeito de currículo e o incício da minha compreensão sobre as ligações entre conhecimento e controle. Meu primeiro trabalho derivou-se de um artigo que eu havia terminado enquanto lecionava em 1974. Nele, eu ainda parecia otimista quanto à alteração de currículo e à educação 'compreensiva' (este otimismo/ingenuidade era uma forte caracterísica em todos os meus artigos até meados de1974).

Este artigo foi submetido ao The Journal of Curriculum Studies e beneficiou-se dos maravilhosos comentários de William Reid, seu editor. Seu auxílio e aconselhamento naquela época foram inestimáveis.

Nas escolas secundárias inglesas, talvez a definição mais comum de currículo é aquela de 'pacote de cursos de estudos oferecidos pela escola': o currículo é algo ‘desenvolvido pelos funcionários’. A definição do pacote que constitui o currículo é feita pelo diretor, inicialmente influenciado por uma série de fatores, que vão desde ideologias, avaliações, a grupos de interesse. O professor individual é um recebedor deste pacote de currículo: sua tarefa normalmente será ensinar apenas uma parte do pacote. Ele recebe um planejamento de ensino, algumas aulas e uma grade de horários. Em resumo, o planejamento do currículo é transmitido ao professor, que deverá receber e executar as decisões tomadas sobre o currículo por seus superiores.

Este processo é repetido na maneira em que a criança recebe o currículo. Ele recebe seu 'pacote de cursos', é instruído sobre quando e com quem fará isso ou aquilo. De maneira semelhante, na sala de aula, o aluno é avisado sobre como cada curso será organizado, qual conteúdo deverá cobrir, e através de que método aprenderá. Na sala de aula, vemos o ‘currículo do professor’ em operação: todas as decisões e definições a respeito de currículo são feitas pelos professores antes da transmissão direta à criança.

Os pressupostos nos quais os currículo dos professores se baseiam estão cada vez mais em conflito com toda a gama de desenvolvimentos da sociedade e da educação contemporâneas. Em todos os níveis da sociedade, as figuras tradicionais de autoridade entram em questão: pais, clérigos, políticos, gerentes, porém ninguém mais que o professor. 
'Não mais a resposta do aluno depende de uma relação mutuamente aceita entre o educador e o educado'. No entanto, à medida que o sistema compreensivo se expande, os problemas da autoridade dos professores tornam-se mais que apenas um aspecto de questionamento geral da sociedade. O currículo dos professores depende de um contrato social entre o educador e o educado, que reflete uma instrumentalidade mútua. Comprehensive schools contêm populações de alunos que possuem uma grande variedade de habilidades e inclinações as quais devem se refletir em uma série de relações instrumentais potenciais. Diante desta diversidade, o currículo dos professores pareceria, mesmo na teoria, simplista demais; a instrumentalidade mútua, o contrato social simples do qual o currículo dos professores depende, jamais existiria em comprehensive school, mesmo que fosse pretendido.

Fundamentalmente, o currículo dos professores parece totalmente destoante dos padrões de autoridade e educação emergentes. Além do mais, a própria natureza do conhecimento transmitido através do currículo dos professores é uma fonte de conflito posterior, devido a suas caracterísicas antiquadas e baseadas em classe. Nesta situação, a escolha pareceria ser entre o uso de métodos mais repressivos na escola, na tentativa de reverter os padrões emergentes e testar os novos modelos de currículo (GOODSON, 1975).

Em 1976, esta postura otimista havia sido redefinida, assumindo um tom mais defensivo - ruminando a respeito das 'forças substanciais que mantinham a transmissão como a pedagogia dominante'.

\section{FAZENDO CONEXÕES}

Este artigo começa a fazer ligações entre meu envolvimento com a reforma pedagógica e política, minha crescente frustração pela obstrução mais genérica das tentativas de reforma de currículo, e uma compreensão emergente dos padrões de organização social e política e do controle na sociedade britânica em meados da década de 1970. Esta percepção emergente sobre a ligação entre o conhecimento e o controle era parcialmente decorrente do trabalho atual na nova Sociologia do Conhecimento, porém, como já vimos, também era resultante de um forte desejo pessoal de investigação. Interessante observar que uma crítica que eu fiz na época, no Society, State and Schooling, de Whitty e Young, especulava sobre a justaposição, comentando sobre sua discussão de que: 
Nem os antigos esquerdistas nem os sociais democratas fabianos pareciam

levar a sério a sugestão de que as políticas educacionais que eles apoiavam meramente forneciam meios mais eficientes de manter o status quo. Certamente, nenhum dos grupos parece ter reconhecido que precisamos examinar 'o que conta como educação', e portanto a maneira na qual as definições prevalecentes da mesma sustenta apenas aquela forma de sociedade que os 'de esquerda’, embora em graus variáveis, desejam mudar.

Eu escrevi:

"Para qualquer pessoa da classe operária que teve experiência na 'grammar school' e na universidade (neste caso, tanto como aluno quanto como professor), esta discussão o atinge com toda a força que a afirmação do óbvio pode fazê-lo. Como Williams observou, quase duas décadas atrás, quando os Comitês Examinadores Locais da Universidade que criaram os níveis ' $O$ ' $e$ ' $A$ ' foram estabelecidos, eram chamados de 'exames de classe média'. De maneira significativa, foi este sistema de avaliação que sobreviveu e que foi introduzido no tecido da educação secundária. A tradição alternativa desenvolvida pela classe operária nos Institutos de mecânica e na educação para adultos ressaltaram todas aquelas coisas que os exames de conhecimento abstrato e clássico de classe média menosprezavam - a relação do conhecimento com a vida contemporânea, o papel dos alunos ao escolher e direcionar os estudos, a igualdade entre a discussão geral e a instrução especializada.

Qualquer um que investigar 'compreensive schools' contemporâneas encontrarão esta tradição alternativa viva e em boas condições. Infelizmente, um exame mais detalhado mostrará que apenas os alunos 'menos capazes' do 'CSE (Certificado de Educação Secundária') e os não-avaliados' recebem o currículo alternativo. Os exames para os níveis ' $O$ ' $e$ 'A' continuam a salientar precisamente estas maneiras tradicionais de conhecimento, derivadas da 'grammar school'. Assim, se for a visão alternativa da classe operária que o atrai, entre no grupo do CSE e da não-avaliação; senão, pegue a rota esquizofrência através dos 'O's e 'B's, BA's (bacharelados) e PhD's (doutorados), longe de casa e dos familiars, afastado de suas raízes e de sua classe" (GOODSON, 1979).

Minha percepção sobre a biografia, sem dúvida, não foi ampliada pela experiência de ensino que tive na Universidade de Sussex em 1975-77. Fui solicitado a dar um curso 'contextual’ sobre 'estilos de vida da classe operária’. O curso era opcional, mas

\footnotetext{
${ }^{9}$ Nota do revisor técnico: o exame nacional para os estudantes de 16 anos na Inglaterra, no País de Gales e na Irlanda do Norte (a Escócia tem seu próprio Diploma Padronizado), o GCSE, foi introduzido em 1988 por um governo conservador. Substituiu o exame para a obtenção do Certificado Geral de Educação de Nível O destinado aos 30\% mais bem classificados nas escolas, e o exame feito pelos que não conseguiam atingir o nível
}

O para obter o Certificado de Educação Secundária, por um único exame que passou a incorporar características de ambos. 
atraiu um grande número de alunos, a maioria de classe operária. No curso, os alunos eram estimulados a escreverem sobre suas reminiscências de vida e escola, de acordo com a retórica do curso 'que a fonte mais importante serão as histórias de vida dos participantes do curso'. Este curso me fez pensar por muito tempo e profundamente a respeito de classe, cultura e currículo e, uma vez que eu estava desenvolvendo, na época, o esboço da minha tese de doutorado, as duas tarefas convergiram. Certamente, compreendi que minhas próprias opiniões sobre a pedagogia e o currículo foram projetadas através de um prisma de classe social que tinha muito em comum com as experiências de outras pessoas de classe operária. Deparei-me com o livro interessante de Albert Hunt sobre sua experiência escolar, como classe operária.

Hunt culpava, acima de tudo, o pressuposto do professor de que, pelo fato de que ele esteja profundamente envolvido com uma disciplina em particular, aquela disciplina precisa ser valorizada e de grande interesse para todas as outras pessoas. Assim, uma disciplina é colocada no centro de toda a educação - e a impossibilidade de fazer aquela disciplina ser valorizada torna-se o fracasso do professor. Mas na experiência de Hunt, assim como na minha e na de meus alunos em Sussex, inicialmente eram as disciplinas em si que faziam com que nada se realizasse: Quase nada em toda a minha experiência educacional formal conectou-se comigo de froma que me envolvesse - a mim, como pessoa. Eu tinha sentimentos, convicções, comprometimentos com idéias e pessoas. Nenhuma destas coisas parecia estar relacionada com meu trabalho... Tudo existia para mim em fragmentos (HUNT, 1987).

Desta forma, comecei a desenvolver um sentido mais amplo de experiência de currículo da classe operária. No entanto, a angústia destas percepções pessoais emergentes, que se desenvolveram na Grã Bretanha em 1976-7, era, de diversas formas, forte demais para suportar. Porque quando se compreendeu a alienação total das disciplinas tradicionais para os alunos de classe operária, o pêndulo político começou a assegurar a reabilitação destas mesmas disciplinas.

Novamente, por força do destino biográfico, fui capaz de assistir a isso em primeira mão. Em 1976, tinha sido convidado a participar como chefe do comitê de orientação de uma disciplina, em uma das principais Bancas Examinadoras. Por acaso, era a mesma Banca que aceitou meu 'O' level em Estudos Comunitários focados no aluno. No 
entanto, eu era um observador em uma reunião do comitê onde aqueles mesmos exames eram eliminados - duas razões foram dadas: não 'compensava financeiramente’ fazer-se tantos exames daquele estilo e tinha havido uma proliferação de 'títulos de disciplinas' (um argumento que posteriormente foi usado para justificar em favor de um Currículo Nacional). Assim, com base em tal aparente pragmatismo, tal conveniência, toda uma subcultura da pedagogia e do currículo foi efetivamente expurgada.

Meu comprometimento com os estudos de doutorado aprofundou-se juntamente com o meu trabalho sobre as origens das disciplinas escolares e sobre o destino dos estudos urbanos e ambientais, e uma nova área inovadora de currículo tornou-se definida. Desta forma, consegui redirecionar minhas investigações sobre a política de currículo, de forma que fornecesse esclarecimento para minha própria experiência escolar, assim como a da minha classe. Desde aquela época, passei a maior parte da minha vida acadêmica em busca de um entendimento mais refinado sobre a história e a política de currículo.

\section{REFERÊNCIAS}

GOODSON, I. F. Curriculum Development and Student Autonomy, Transcript, n. 2, November, p. 8, 1973 (1).

. Developing Contexts for Autonomous Learning, Forum, May,1973 (2).

. Man In Time and Place, Outline Plan, Stantonbury Campus, 1974.

. 'Personal Points of Entry'. Notes for I.F. Goodson, The Making of Curriculum

(Falmer: London, New York and Philadelphia), 1988.

.., 'The teacher's Curriculum and the new reformation', Journal of Curriculum

Studies, November, 1975.

. Towards An Alternative Pedagogy. In WHITTY, G., and YOUNG, M., (eds.),

Explorations in the Politics of School Knowledge. Nafferton: Drifield, 1976. p. 128 - 138.

. Review of M. YOUNG and G. WHITTY, Society, State and Schooling. In:

Socialism and Education, March, 1979.

GOODSON, I. Currículo, narrativa e o futuro social. Revista Brasileira de Educação, v. 12, n. 35. maio/ago 2007, p. 241-252. 
. Questionando as reformas educativas: a contribuição dos estudos biográficos na educação. Pro Posições, v. 18, n. 2 (53). maio/ago 2007, p. 17-37.

HUNT, A. Hopes of Great Happenings (Eyre Methuen). See GOODSON, I.F., - 1987, Introduction, School Subjects and Curriculum Change (Falmer: London, New York and Philadelphia), 1976.

MCMULLEN, T., (Probable author). Briefing papers, Countesthorpe College, 1970.

Times Education Supplement, Jan. 7, 1970.

WALKER, R. Teaching That's A Joke, SAFARI Occasional Paper, n. 4, University of East Anglia, 1973. 